\title{
THE PROBLEM OF THE AGED AMPUTEE
}

\author{
By Marjory WarRen, M.R.C.S., L.R.C.P. \\ Consultant Physician, Geriatric Unit, Deputy Medical Director, West Middlesex Hospital, Islezoorth, Middlesex
}

It is well known that the population is ageing not only in this country, but also in many other countries. Morbidity is greater among the older than among the younger members of the population, and there is therefore a high and increasing incidence of those degenerative conditions which result in amputation of a limb or part of a limb.

Amputations which may be of the upper or one or both of the lower limbs usually follow degenerative vascular changes, a malignant condition or trauma. In the elderly by far the commonest condition necessitating amputation is gangrene, resulting from arteriosclerosis-including the so-called ' diabetic gangrene,' which is most probably also arteriosclerotic in origin. The changes occur much more frequently in the peripheral vessels of the lower limb than in those of the upper limb.

This article will not include a detailed discussion of the aetiology and underlying pathology of conditions leading to amputation nor will it describe surgical techniques. It sets out only to prescribe in detail the correct management of the elderly amputee and to emphasise points necessary to his good treatment.

It must be accepted therefore at the outset that unless adequate overall and detailed care be undertaken much of the benfit of surgery will be lost, for the final success of the patient rests upon more than surgical skill. Indeed, the actual surgical removal of a limb, essential as it is, may be the simplest part of the treatment. In every case of amputation, however old and/or frail the patient may be, it is important for the surgeon to bear in mind that the stump must be adequate to carry a pylon or prosthesis.

A good psychological approach before operation for amputation can do much to reassure. Every amputee following operation needs very careful management, including full rehabilitation as well as general treatment, physical and psychological. Throughout treatment, too, it is essential that attention be given by the almoner (medical social worker) to the patient's social conditions, for, without this, return to his home may become impossible and much independence may therefore be lost.

Among elderly patients ,two important facts must be remembered-firstly, that a variety of ले arteriosclerotic manifestations are liable to occur in the same patient, namely coronary insufficiency, ischaemic heart disease, cerebro-vascular accidents $\vec{\omega}$ with resulting hemiplegia, Parkinson's disease, $\frac{\mathbb{D}}{0}$ etc.; and, secondly, the frequency with which a multiple pathology is found.

Both these factors add to the difficulties of full and complete rehabilitation-but neither the $\overrightarrow{0}$ presence of other arteriosclerotic manifestations on nor yet the occurrence of multiple pathology must. be used as an excuse for undertreatment. Such patients, after an amputation of one or even both lower limbs, can be restored to considerable personal independence, when full and adequate treatment is carried out.

A study of such amputees ${ }^{1}$ has shown that nearly $\overrightarrow{\vec{O}}$ all suffer from other serious : handicaps and that 3 many develop additional handicaps while actually under treatment. These episodes limit progress - and cause delay in, but should not be used to cease, rehabilitation. In spite of these set-backs and from the total experience of centres treating these patients it is the opinion that most amputees, single and double, should be educated to walk again using a single pylon or two rocker pylons. It has, moreover, been found that when $\frac{\text { s }}{3}$ treatment is successful, then in the majority of $\frac{7}{O}$ cases the patient can and does become almost completely independent for most of his personal $N$ needs. He can leave the hospital and live at home with his own people or can be accepted into a residential home, where he can enjoy a reasonably $\omega$ normal and interesting life.

Without such facilities all elderly amputees, and

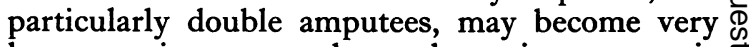
heavy nursing cases and as such a serious economic burden to the community. 


\section{Amputation of Lower Limb}

The amputation of one lower limb may be followed by an amputation of the other and, although in principle the general pattern of treatment is the same for both, there are essential practical differences in the management of a single and a double amputee.

The different phases of treatment for both include:

(I) Pre-operative care.

(2) Post-operative and pre-pylon care.

(3) Post-pylon care.

(4) Maintenance and follow-up care.

\section{(I) Pre-operative care}

This includes care of potential amputees and those patients who, having already lost one lower limb, are about to lose the second and so to become a double amputee.

\section{(a) General Care}

With elderly amputees it must be remembered that in the majority of cases the gangrene is essentially a manifestation and part of a medical condition. There is, therefore, much to be gained for the patient, when he is seen by a physician prior to amputation and then transferred back to his care for full rehabilitation as soon as the surgical technique is completed, that is when the sutures are out and the wound healed.

It is important, whenever possible, to see the patient before operation in order to undertake a thorough medical review and to reassure him, allay his fears and try to minimise the feeling of frustration concerning his disability and impending loss of independence. Such medical review must include correction of all conditions found which need treatment, including cardiac failure, glycosuria, impaired sight and/or hearing, etc.

Advice to the patient at this time concerning his future should be guarded, but as optimistic as is reasonable and he should be told of the opportunuties for re-education. Whenever it is possible for the patient to meet and talk to another amputee who is doing well, this should be arranged, for such a contact is often most encouraging to the ' new' patient, who at this time is generally miserable, depressed and very apprehensive.

When this opportunity is not possible, a talk after his amputation is helpful. The knowledge that he can become ambulant in a self-propelled wheel chair of his own and that he may be able to get about on pylon(s) gives ground for considerable optimism to a patient, who feels doomed to permanent dependence upon others and can see no future beyond his bed (and that perhaps in a hospital).

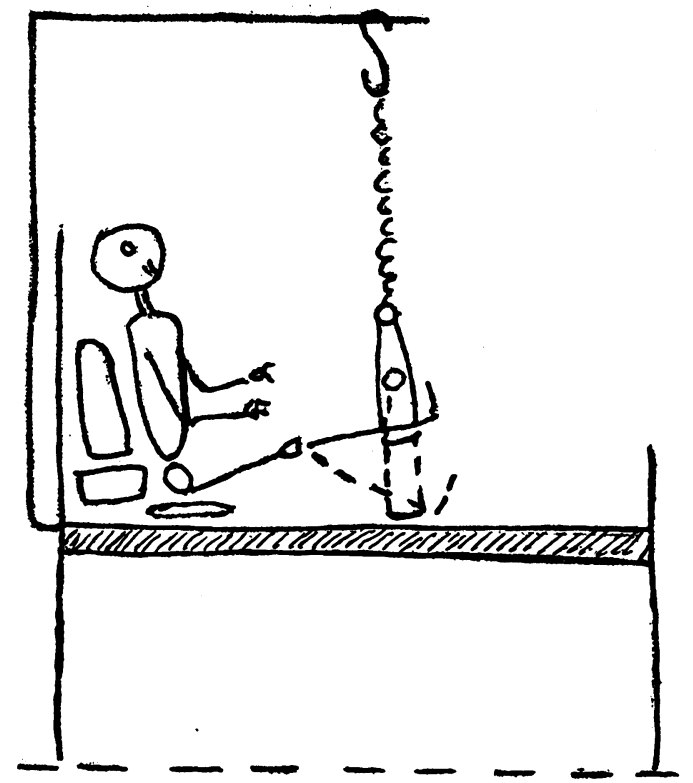

FIG. 1.-Use of suspension method in prevention of contractures and pressure sores of heels.

(B) Local Care

Before amputation there is often a tendency for the patient to develop flexion contractures of the affected limb, including a flexion and/or adduction contracture of the hip. When such contractures occur, they are usually due to painful spasms of the limb and malpositions in bed, and when established are difficult to overcome. Flexion contractures of the opposite limb may also occur, especially in patients with arthritis-but all these must be prevented. See Fig. I. Such contractures when present complicate the fitting of the pylon, making weight bearing more difficult and balance less stable. It is equally important to prevent pressure sores, especially of the ' good heel ', and particular care in nursing must be established as pressure sores easily develop in such patients. Such conditions, when they occur, retard postoperative progress and so must be avoided.

\section{(2) Post-operative and pre-pylon care}

Within 48 hours of amputation the patient should be encouraged to exercise his stump with full joint movement of hip (and, when present, knee), with especial attention to full extension and abduction. The opposite lower limb should also be kept in good condition and free from contractures and/or pressure sores. The patient should be out of bed two to three days after operation and fully dressed not later than ten days after operation. Dressing in everyday clothes considerably improves morale and the patient should be encouraged to attend to this and other 
personal needs himself, within a few days of his amputation. As soon as the patient sits out of bed in an armchair he should, if a single amputee, wear a leather lace-up walking shoe on his good foot to protect the foot from trauma, in order that he can conveniently take weight on the foot when standing and for improvement of morale.

As soon as possible after sutures are removed and when the patient is fully dressed he should be provided with a self-propelled wheel chair fitted with one, or preferably two, brakes in front, which he should occupy all day except when doing éxercises. This use of a wheel chair not only gives a measure of independence and freedom, but also allows a good deal of useful physiotherapy for the trunk and upper limbs.

Occupational therapy and physiotherapy should be utilised as much as possible at all stages. Occupational therapy will vary considerably according to the tastes, mental capacity and physical state of the patient, but should be full and continuous. The patient may take part in occupational therapy as individual exercise or as a member of a team, e.g. in games-such as pillow fighting, deck quoits, ball games, archery, etc. All these games encourage good balance, accuracy of movement, improved use of the upper limbs and a mental alertness and ambition.

Individual exercise, either as occupational therapy or as physiotherapy, emphasises the need for full movement of the hip joints, including flexion, extension, abduction and adduction of stumps, fixation of the hips and lifting of the trunk by the use of an overhead pulley. A combination of these activities prepares the amputee physically and psychologically for maximum independence and later for the use of pylons.

So far such general principles apply equally to all amputees. The details of practical rehabilitation of the single and double amputee must, of course, differ and will be described separately. In all instances, however, treatment must be adapted to the patient, considering his personal disabilities.

\section{(A) Single Amputee}

Fully clad and in a leather lace-up shoe, with sutures out and other medical conditions controlled, the new amputee should start on a planned pattern of treatment in preparation for a pylon and later, perhaps, a prosthesis. The plan of treatment includes:

i. Care of stump.

ii. Exercise in a wheel chair.

iii. Bed-end exercises.

iv. Exercises in hopping along on the flat and on the stairs.

\section{i. Care of stump}

The stump should be regularly bandaged according to the Roehampton method and the aim is to produce a conical stump. Exercises, including full movement of the stump(s), if undertaken correctly, should prevent contracture of the joint(s).

\section{ii. Exercise in a wheel chair}

As early as possible the patient should get about in a self-propelled wheel chair, both indoors and out of doors. He should learn to get from bed to chair and from chair to bed, using, when necessary, a 'shuffle board.'2 See Fig. 6 . During the whole of this period the patient has the freedom of the ward and can go to toilet unaided, although in the early stages he may need help in getting from his chair to the toilet seat.

\section{iii. Bed-end exercises ${ }^{3}$}

These exercises are done by the patient sitting comfortably and well back in an armchair at the end of his bed. See Fig. 2. Such a chair should have a firm seat, $I 7$ in. to 18 in. from the floor and be provided with a sorbo air ring, as this is less liable to slip than a cushion on a polished seat. An upholstered chair, and especially one with internal springs, is more difficult for the patiento to rise from. If the patient is very short a lowerg chair may be needed, in order that he can sit, as described above, with his foot flat on the floor.

The rail at the end of a hospital bed ( 33 in. above the floor) gives support to the patient when he stands up.

A wooden bed-end board, $4 \mathrm{ft}$. in length and 4 in. $x 2$ in. on section, placed on the floor across the foot of the bed (on its $4 \mathrm{ft}$. $\times 2$ in. surface) acts as a foot stop. Exercises in order of succession are as follows-using the bed-end board in all instances as a foot stop:

(I) Patient is encouraged to lift himself in the seat of his chair by hand support on the arms of the chair. See Fig. 3. This exercise is a great help to all who nurse him as it allows clothes to be pulled up and down easily, permits the patient to change his position and relieves prolonged pressure on the sacral area.

(2) Patient should learn to stand up from a sitting position leaning on the bed-end rail (see Fig. 4) and then to sit again in his chair.

(3) While standing at the end of his bed the patient must learn to stoop by flexing his sound leg and then to stand upright again.

(4) Later he should learn, using the above exercise, to hop across the end of his bed. See Fig. 5. 


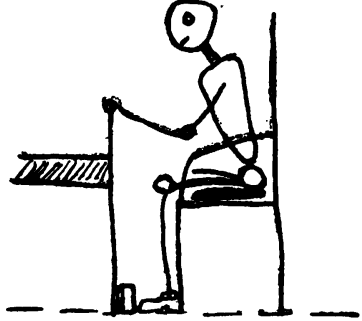

Fig 2 .

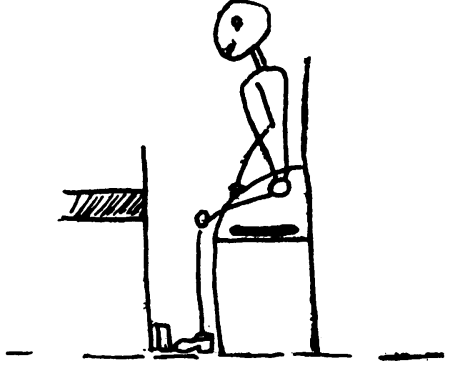

Fig. 3



Fig 4

Fig. 2. - Single amputee sitting in armchair at bed-end with foot board in position to act as foot stop. Sitting leaning on bed-end rail.

Fig. 3.-Raising trunk leaning on chair arms.

FIG. 4.-Leaning on bed-end rail in standing position.

Walking Exercise-on the Flat

(I) When quite competent at the bed-end, the patient should practise walking in a 'walking lane' holding two rails, but without foot stop. See Fig. 7.

Progression is by a series of hops, again using the method learned at his bed end.

(2) As soon as possible he may attempt walking with one rail and one 4-legged stick ${ }^{4}$ and later with two 4-legged sticks. The use of 4-legged sticks is usually easier and safer than the use of crutches and so is a method to be preferred. Moreover, elderly patients prefer such sticks and there is usually no object in replacing them with single sticks unless the patient feels quite secure with the latter.

\section{Walking on the Stairs}

By the time that a patient can hop along on the flat using two 4-legged sticks, it is but a small step further to hop upstairs using two stair rails. See Fig. 8. When on the stairs, he must grasp the hand rails well forward, so that he can pull himself upwards. This hopping on the stairs is not much more difficult than hopping on the flat and quite old and even obese patients manage well in the majority of cases. Hopping downstairs, holding two stair rails, is generally considered easy even by patients. . If possible a patient should hop $u p$ a few stairs before hopping down, because although going up is more difficult, there is usually less fear in facing an ascent.

Anticipation of going on stairs always produces some apprehension and the average patient faces a flight upstairs with less fear than a flight downstairs. By contrast turning and coming down will be easier and the patient who has undergone some nervous strain in mounting the stairs will actually feel relieved as he hops down.

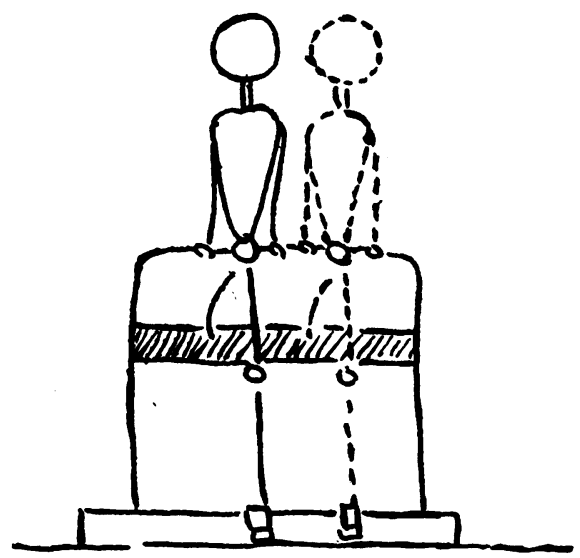

\section{Fig 5 .}

Fig. 5.-Hopping sideways across bed-end with bed-end board as foot stop.



FIG. 6.-Getting from wheel chair to bed using shuffle board. 


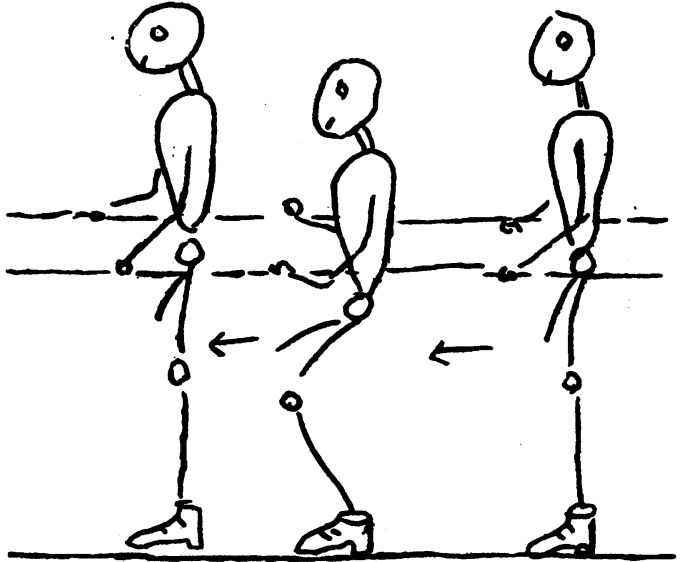

Fig. 7.- Hopping forwards between parallel rails.

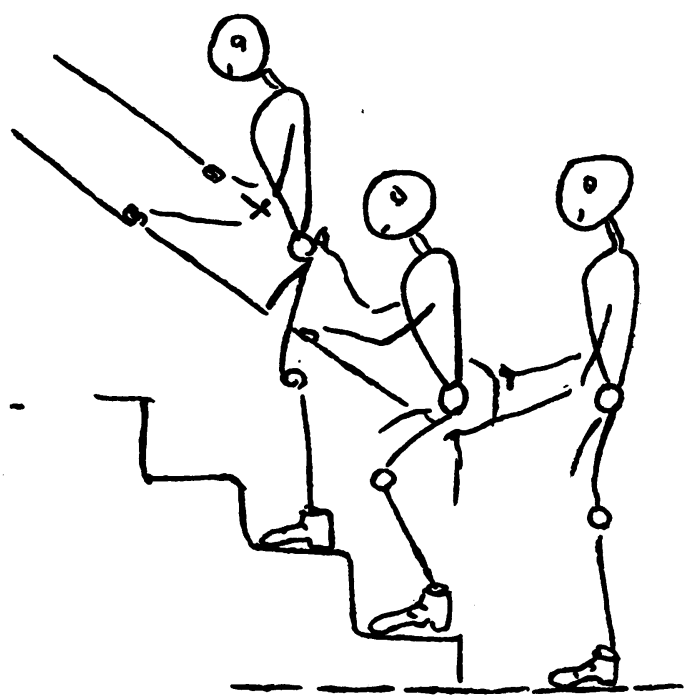

Frg. 8.-Hopping on the stairs using two rails.

In order to get good results it is essential that these exercises be undertaken in correct progression always mastering one before proceeding to the next-and that the patient's confidence be maintained throughout treatment. If the patient has been well taught, stage by stage, and if his confidence has been maintained, then he will gradually accomplish these three stages: standing, (ii) walking, (iii) climbing stairs.

The whole of this period of education is directed towards the use of a pylon and in some cases later of a prosthesis. The main points in this phase of treatment include:

(I) Development and maintenance of a good stump.

(2) Development of free and unimpeded movement of the hip (and knee when present) on the amputated side-including the ability to fix the hip and the knee. This latter is most important.

(3) Development by the patient of selfconfidence and good morale.

Throughout this period of training the therapist should be near to the patient, but should refrain from holding or touching him. As soon as a patient is held he loses morale and cannot estimate how good is his own effort.

\section{(B) Double Amputee}

Fully clad, with sutures out and other medical conditions controlled, the new double amputee should also start on a planned pattern of treatment in preparation for short rocker pylons.

The double amputee is easier to teach when his amputations are at the same level-a point worth remembering by the surgeon at the time of the operation.

The plan of treatment for the double amputee includes:

(a) Care of stumps.

(b) Exercise in a self-propelled wheel chair.

(c) Exercises on the bed.

(d) Exercise on the bed, at the bed head.

(a) and (b). The care of stumps and exercise in a chair are the same as for the single amputee except that when he is first in a chair the patient must be strapped into it so that he does not overbalance and fall. Such a fall, apart from injury, is very demoralising, both for the patient and for staff, undermining confidence and retarding progress.

When the patient has been provided with a wheel chair, fitted preferably with two brakes operated in front, he should learn to get from his bed to his chair and back again from his chair to his bed. This may be done in a variety of ways:

(i) The patient may use a shuffle board.

(ii) The patient may lift himself forwards from chair to bed. This is especially applicable when there is no gap between chair seat and mattress.

(iii) The patient may lift himself from the seat to the arm of the chair and then from there on to his bed. This is done with chair placed beside the bed.

Especially in the case of the double amputee the full and continuous use of a wheel chair does much to restore self-esteem.

(c) Other Exercises on the Bed

(i) Exercises for the upper limbs and trunk which are important in gaining strength in the arms, which will take the weight when in pylons and using tetrapods; and 

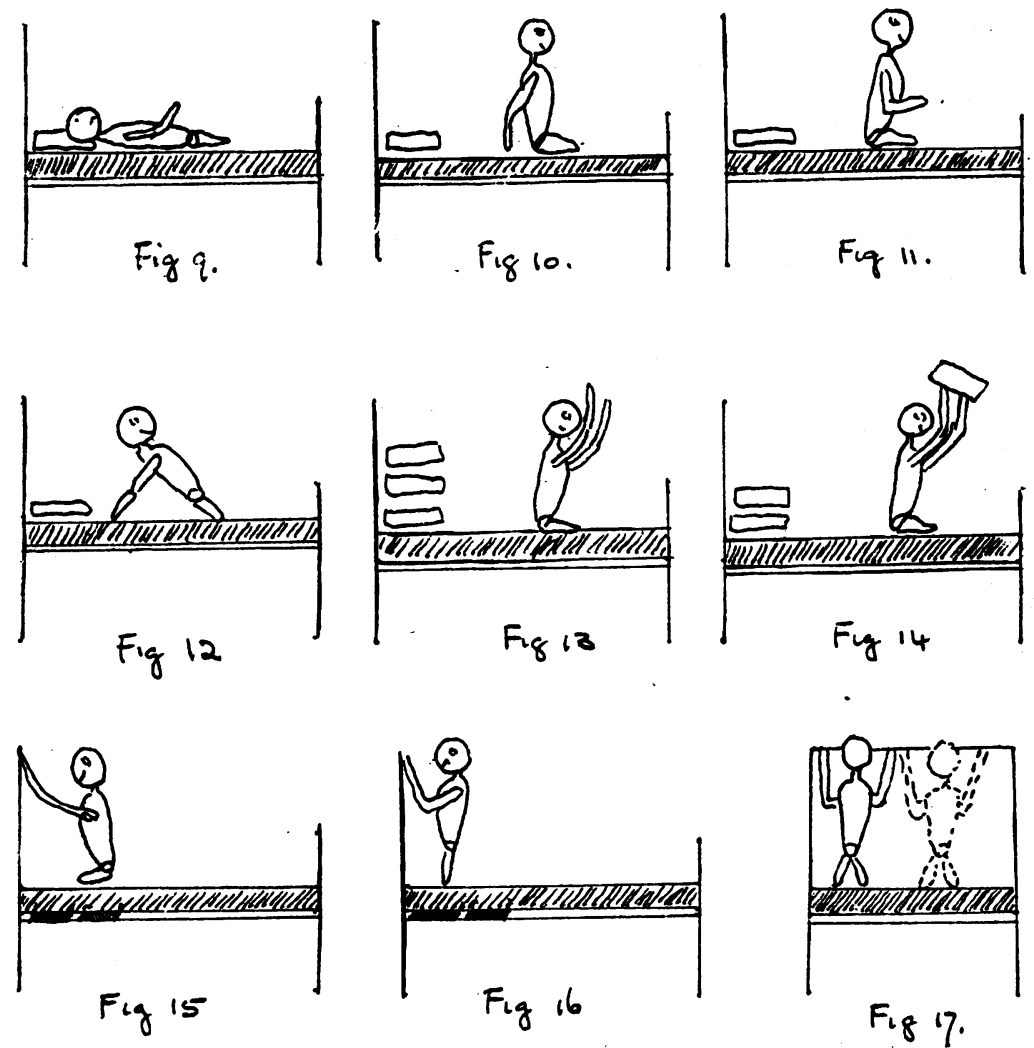

Figs. 9, ro and 11.-Show double amputee sitting up from prone position on his bed-unaided.

Fig. 12.-Double amputee, with hands behind on the bed fixing hips and pelvis.

FIGS. 13 and 14.-Double amputee learning good balance-here seen throwing pillows.

Figs. I 5 and 16.-Double amputee rising on to stumps from sitting position. Fracture boards under the mattress give extra stability for this exercise.

Fig. 17.--Shows double amputee walking on stumps across the head of his bed in preparation for use of rocker pylons.

in getting good control of the trunk in the erect position.

(ii) Exercise in rising from the prone to the sitting position on his bed (see Figs. 9, Io and II), without counter weight on his stumps or other help. This can be achieved by all patients if properly reeducated. While sitting on his bed the patient can place his hands on the bed behind him and, raising his buttocks from the bed and resting on his stump ends, fix his hips and pelvis (see Figs. Io and 12).

(iii) Exercise in balance can be undertaken by getting the patient to sit on his bed and raise his upper limbs above his shoulders and later, in this position, to throw his pillows from his bed to a nearby chair (see Figs. 13 and 14 ).
(D) Exercise on the Bed at the Bed Head

Exercise in rising on to the stump ends from a sitting position, and in sitting again. This exercise can well be undertaken on the bed using the rail at the head of the bed-and is easier when boards are placed under the mattress to give additional rigidity. In this position, with practice, the patient may stand first on one stump and then on the other, and so can learn to walk across the bed holding on to the bed head, which should be not less than 20 inches or $50 \mathrm{~cm}$. above the mattress level (see Figs. 15, 16 and 17 ).

\section{Pylons-Structure}

\section{(a) For the single amputee}

The result of much research work in the Limb Fitting Centre at Queen Mary's Hospital at Roehampton has led to a number of new designs for pylons which are light to wear, easy to put on and 
simple to use. These offer great advantages over the older types. It is important to be very sure that the length of the pylon is correct. An oversight in this detail is not uncommon.

\section{(b) For the double amputee}

The modern short rocker pylons have been designed. These pylons are light in weight, average $8 \mathrm{lb}$. (3.6 kilograms), and measure approximately 24 inches $(60 \mathrm{~cm}$.) from belt to floor. The buckets are made of plastic material held in position by a light metal frame and attached to the waist belt by a strip of metal capable of movement about a simple joint. The curved rocker foot pieces are made of light plywood and point backwards, enabling the patient to throw his weight forwards when walking.

\section{Post-pylon Care}

In the case of both single and double amputees very little difficulty is experienced in the education of walking in pylons provided that the patient has been properly prepared for them by methods just described.

\section{Single Amputee}

In the case of the single amputee, provided the pylon fits well and is comfortable, he continues to exercise as he did before he had his pylon and he finds standing, walking and stair climbing easier with the additional support. He should then graduate to the use of two 4-legged sticks, but will most probably soon take one 4-legged stick plus one single stick and later two single sticks. For those patients who continue to feel the need of tetrapods, no attempt to take them away should be made.

In climbing stairs the patient raises the sound leg and draws the pylon up behind. In descending he lowers his pylon first while flexing the hip and knee of the oncoming sound limb which follows. The patient must, before education is complete, be taught to put on his own pylon, which is not a difficult procedure, but which is important to his final independence.

\section{Double Amputee}

Use of pylons on the flat

When the patient is as independent as possible and competent in the exercises described, and NOT before, he should be provided with pylons and these should be made with all speed. It is useless to provide pylons until a patient is able to balance himself well and to stand on his stump ends as previously described, and too early provision will only frustrate a patient and retard progress.

As soon as he is ready, however, pylons should be provided and it has been found from experience that the sooner he is fitted with pylons the shorter is the time needed to complete his re-education. In the earliest stages with pylons the best method of education is to use two parallel rails-the 'walking lane.' Following the use of the two rails the majority of elderly patients need two 4-legged sticks in learning to walk and there is no good reason for withholding these and insisting on the use of ordinary sticks. In the past some patients have been regarded as failures until the value of the four-legged sticks was appreciated.

\section{Use of pylons on the stairs}

As soon as a patient is competent to walk on the flat with two 4-legged sticks and without help then, in the majority of cases, he should attempt stairs. The stairs must be provided with a rail on each side of the staircase.

It has been established beyond any doubt that a patient should descend stairs backwards and ascend forwards, when using the rocker pylons. To descend forwards throws the patient's weight to the edge of the stairs, and with narrow stairs actually beyond the edge, with the inevitable feeling of danger and tendency to fall forwards. Whereas descent backwards leaves the weight close to the rise of the stairs in a safe position. It was lack of this knowledge which prevented the re-education of earlier patients on the stairs and so deprived them of additional independence.

In spite of the simple structure of the modern short pylon, elderly patients usually find it difficult to get into them without help, but this should be learned whenever possible. Methods include:

(I) Lying on the bed patient slips his stumps into the buckets of his pylons and then lifts his pelvis, while still on the bed, in order to draw the belt up over his pelvis before sitting up to fasten it.

(2) Sitting on the edge of the bed the patient places his pylons on the floor and slips into them in a vertical position, leaning against the side of the bed while he fastens the belt with a single buckle.

This method is made easier when a heavy board, provided with rubber non-skid patches on the under surface and wooden channels on the upper surface, is placed on the floor and the pylon feet are placed in the channels. By this method the pylons are less likely to slip and/or rotate and greater stability is provided.

\section{Post-pylon Care and Maintenance}

An essential service to the elderly amputee is good continued supervision in order to note as early as possible any fault or change in the pylon 
or any deterioration of the patient and/or his living conditions.

Delay in repair of, or adjustment to, a pylon may well cost a patient much loss of independence. While not wearing his pylon and with less exercise than usual, he may put on so much weight that the bucket no longer fits. It is not surprising that during such a period he becomes frustrated and loses self-respect.

When pylons need adjustment this should be done at once and with no alteration that is not essential. Wearing a pylon is difficult for an old person and sudden changes of design put unnecessary strain upon him. Pylons need to be very simple indeed. Limb fitting centres should work in the closest liaison with the physician in whose care the patient has had his rehabilitation and general medical treatment.

\section{Pylon versus Prosthesis}

In younger persons the pylon is usually regarded as the first step towards the use of a prosthesis. In a large number of elderly persons it is medically unwise to abandon the pylon and provide a prosthesis and this applies particularly to the double amputee. The prosthesis is heavier, more difficult to manage and apart from aesthetic purposes, has little to recommend it. The mechanism of flexing the knee when sitting is certainly helpful when it is operated accurately, but this is not always achieved by the old person. Some types of modern pylon are fitted with a simple knee joint which allow flexion and give, in this respect, advantages similar to those of the prosthesis.

In the case of the double amputee the added height of a prosthesis seriously interferes with balance, and often the change from pylons to prosthesis is one of great mental and physical strain. The physical strain is most often manifest by cardiac failure with oedema of stumps making the wearing of the prosthesis difficult.

It is sometimes the patient who makes the request for a prosthesis, but a change from pylon to prosthesis should always be discussed at a consultation between the physician in charge of the patient and the Limb Fitting Centre, before a decision is taken. Even a change in the detail of a pylon may be too much for a patient to manage and such a suggested change should be discussed with the physician in charge before alterations are made. Those who work with this problem amongst the elderly have frequently seen the amputee, perfect in pylons, converted into an abysmal failure in prostheses.

Prostheses for the elderly should be the exception rather than the routine, and should only be provided after a careful and full medical review.

\section{Upper Limb}

The treatment of an elderly patient with an amputation of an upper limb is essentially the reeducation of the patient to undertake personal needs with one instead of two hands and to transfer to the left hand (in cases of an amputation of the right upper limb) those things which he has hitherto done with the right. The general management of the patient should be as already described for patients who sustain an amputation of the lower limb. In the early post-operative phase it may be necessary to supervise balance in walking and to treat conditions of psychological trauma. Although prostheses are available seldom would it be considered necessary to burden the elderly patient with one, except on occasion for aesthetic purposes.

\section{Difficult Problems}

Many elderly amputees present with very difficult additional disabilities which include:

(I) One above knee and one below knee amputation.

(2) An above knee amputation combined with a hemiparesis.

(3) An above knee amputation with an ununited fracture of the neck of one or other femur.

(4) A bilateral amputation with blindness.

Such combined disabilities must always be accepted as a challenge and treated on individual lines.

\section{Summary of General Principles}

(I) Patients must be treated fully with meticulous care of detail and in continuity.

(2) When possible patients should be seen and assessed medically and psychologically before amputation by the physician in whose care they will be after amputation.

(3) Education should be aimed at full independence.

(4) When necessary aids such as sticks (single or tetrapod), chairs, gadgets, rails and ramps should be provided.

(5) Post-pylon care and maintenance must be early and efficient if success is to be maintained.

(6) With full team work and a planned pattern of treatment most amputees should become independent for personal needs, proficient in a wheel chair and able to walk on the flat and on the stairs.

I wish to acknowledge the help that I have had from, a number of medical colleagues and especially to mention Dr. M. M. Pam and Dr. J. Kaminski.

References continued on page $45 \mathrm{I}$ 
trigger areas, the pain spots which are seen so characteristically in this condition and no other?

That the virus of herpes simplex is present in the majority of patients suffering from trigeminal neuralgia is evidenced by the fact that complement fixation tests are positive in 100 per cent. of cases tested.

We have performed complement fixation tests upon a consecutive series of patients operated upon at the South-East Metropolitan Regional Neurosurgical Centre, and in all of the subjects tested anti-bodies were present in high concentration in a serum dilution of $I$ in 80 or $I$ in 40 .

There is likewise the evidence provided by the high incidence of post-operative outbreaks of herpes simplex. Cushing ${ }^{12}$ described a form of facial herpes following section of the trigeminal sensory nerve and regarded it as a form of herpes zoster; Richter ${ }^{13}$ and more recently Carton and Kilbourne have demonstrated by inoculation experiments that this eruption was due to the virus of herpes simplex. The incidence of postoperative herpes has been assessed by Epstein ${ }^{14}$ at approximately 25 per cent. Carton and Kilbourne have estimated that minute vesicles can be detected with the aid of a lens in over 90 per cent. of cases. In our experience outbreaks visible to the naked eye occur in approximately 60 per cent. of the 175 cases operated upon in recent years at the SouthEast Metropolitan Regional Neurosurgical Centre and bear no direct relationship to the occurrence of pre-operative herpes simplex. Usually the eruption is seen about 24 hours after operation and no further attacks occur, but in rare cases postoperative herpes may be recurrent.

There is sometimes a very close relationship between the distribution of the post-operative herpes and the distribution of the pre-operative pain, and I would like to quote one final case. A Mrs. E. S. had for three years suffered from severe recurrent neuralgia involving the second division of the nerve. A complete Sensory Root Section was performed producing complete anaesthesia in all three divisions in April I947. Two days later she developed a massive outbreak involving the whole territory of the second division associated later with crusting in the nose and ulceration of the ala, which was so severe that in April I 948, I referred her for plastic repair to Mr. F. T. Moore who produced a most satisfactory cosmetic result by grafting in a portion of the cartilage of her ear. It appeared to me to be something more than a coincidence that so severe an outbreak should be confined exclusively to the territory of the second division, which had been the principal site of her pain, in a patient in whom the entire sensory root had been divided. Bearing these facts in mind, together with the negative character of any alternative evidence, I would suggest that the possibility of virus infection being the cause of trigeminal neuralgia is well worthy of further consideration.

Primary infection with herpes simplex is common and following this the virus persists in the body as indicated by the persistently high titre of antibiodies. The virus thus persisting seems to have a special affinity for the trigeminal nerve, as indicated by the frequent recurrent outbreaks of herpes simplex whether preceded by neuralgia or not, in the maxillary and mandibular areas. It is further indicated by the fact that postoperative herpes is almost exclusively seen following operations involving directly or indirectly the sensory root of the trigeminal nerve and its deeper connections.

All this evidence would suggest that there is a reservoir of the virus of herpes simplex in relation to the trigeminal territory somewhat on the lines originally advanced by Goodpasture, that the virus of herpes simplex may reside indefinitely in a latent form in some central or peripheral portion of the trigeminal nerve. It is possible that in a very small proportion of infested individuals the consequence of such nidification of the virus, may be Tic Douloureaux.

A paper developed in association with Dr. Simon Behrman and read to the Society of British Neurological Surgeons at Leeds 1952.

\section{REFERENCES}

I. BEHRMAN, S., and KNIGHT, G. C. (1954), Neurology, 4, 525 .

2. BEHRMAN, S., and KNIGHT, G. C. (1956), Ibid., 6, 363.

3. CARTON, C. A., and KILBOURNE, Ed. (1952), New Engl. F. Med., 172, 246.

4. CUSHING, H. (1920), Amer. F. med. Sci., 157, r6o.

5. EPSTEIN, L. (1948), Acta. psychiat. (Kbh.), 13, 23.

6. FRIEDENWALD, J. S. (1923), Arch. Opthalmol., 52, 105.

7. GOODPASTURE, E. W. (I929), Medicine, 8, 223.

8. HARRIS, W. (1937), ' Facial Neuralgias,' Oxf. Univ. Press.

9. LOVE, J. G., and SVIEN, H. J. (I954), f. Neurosurg., II, 499.

10. RICHTER, R. J. (1944), Nerv. Ment. Dis., 99, 356.

II. SHEI.DEN, C. H., PUDENZ, R. H., FRESHWATER, D., and GIVE, G. L. (1958), Ұ. Neurosurg., 12, 123.

12. SMITH, M. C. (1954), Proc. roy. Soc. Med., 47, 788.

13. STENDER, A. (1954), ₹. Neurosurg., I1, 333.

I4. TAARNHOJ, C. (1952), Ibid., 9, 288.

3. Bed-end Exercises as described in 'Care of the Hemipleg: $c$ Patient,' Med. Press, May 5, 1958, Vol. CCXIX, No. 5687 .

4. Four-legged Sticks as described in 'Physical Agents' in 'The Treatment of Chronic Patients' under paragraph 'Medical Aids,' Medical Annual, 1955, p. 30I, 